\section{The fallacy of comparing diagnostic radiation with background radiation; and the need to learn from past mistakes}

To the Editor: The subject of radiation exposure for diagnostic purposes is currently a 'hot' topic, and it is appropriate that the debate around this issue is given exposure in the pages of the SAJR. I would like to comment on a few of the points raised by Dr Tipler in his article that appeared in the June 2010 SAJR.

The advent of CT scanning has revolutionised the practice of medicine. No one in their right mind would argue that, when a CT scan is performed correctly and for an established indication, the benefit of the examination outweighs the risk (in terms of radiation exposure) many times over.

Dr Tipler, however, states: 'We all know CT is being overused.' This goes to the heart of the matter and in particular to the danger posed by self-referral by specialists outside of Radiology, should such specialists obtain a licence to operate a CT scanner.

Dr Tipler mentions the issue of background radiation. $\mathrm{He}$ also makes the statement that background radiation on the coast of Brazil exceeds $150 \mathrm{mSv}$ a year. These issues require some clarification. With regard to the comments about Brazil, it is true that some, but by no means all, beaches contain radioactive monazite deposits. These deposits give the sand a characteristic black colour - unlike the golden sand of the beaches of Rio de Janeiro. If one camped out specifically on one of the monazite-containing beaches for a prolonged period, it would be possible to receive external radiation exceeding $150 \mathrm{mSv}$ a year. Besides Brazil, monazite deposits are also found in India and China. The dose of radiation to people living in these areas is on average $5-6 \mathrm{mSv}$ per year. Individual doses up to $32 \mathrm{mSv}$ per year have, however, been reported. Of note is that in areas of high background radiation, an increased frequency of chromosome aberrations has been noted repeatedly. ${ }^{2}$ More research is needed to quantify the effects of the high background radiation levels in these areas.

Regarding the red herring of background radiation as argued by the radiation dissidents, I would quote the following:

'A criticism of a conservative approach in the use of ionising radiation is that we are all daily exposed to background radiation and have evolved cellular mechanisms capable of repairing damage caused by ionising radiation. The counter-argument is: "Sola dosis facit venenum." (It is only the dose which makes the poison.)

'The average individual dose received from background radiation is approximately $3.6 \mathrm{mSv}$, delivered over the period of a year. A CT scan of the abdomen and pelvis delivers $10 \mathrm{mSv}$, approximately 3 times this dose, in a few minutes. This is not what our repair mechanisms have evolved to cope with. An analogy might be the cellular mechanisms evolved to metabolise alcohol. A $750 \mathrm{ml}$ bottle of brandy drunk over a period of a few minutes is likely to have a fatal outcome. The same volume of brandy, if taken over a year, equates to marginally more than $2 \mathrm{ml}$ per day; an amount unlikely to pose a challenge to the cellular metabolic systems.'

In conclusion, Dr Tipler alludes to the linear no-threshold theory and the information gleaned from the Japanese atomic bomb survivors, on which much of the BEIR 7 report is based. Although easy to criticise, these are not the only sources of information with regard to the risks of radiation. I quote again:

'Many of the early pioneers of the science of radiation and radiology were exposed to high doses of radiation and succumbed to its carcinogenic effects. In addition, from the 1930s to the early 1960s, ionising radiation was used to treat many benign conditions. These included sacro-ileitis, and postpartum mastitis. Numerous children received x-ray screening and radiation treatment for "enlargement" of the thymus gland and many have subsequently died from radiation-induced malignancy. These treatments were terminated when the association with the subsequent development of cancer became clear.'

Further evidence for harm from injudicious medical use of ionising radiation has come from the large radiation doses given by bi-weekly fluoroscopic (non-image intensified) screenings to determine whether an iatrogenic pneumothorax, performed for the treatment of tuberculosis, was still present. Fifteen and more years later, the incidence of breast cancer on the side subjected to fluoroscopy was doubled.

Unfortunately, we have short memories. To paraphrase George Santayana: 'Those who do not learn from the mistakes of history are destined to repeat them.' Samuel Taylor Coleridge put this more philosophically: 'If men could learn from history, what lessons it might teach us! But passion and party blind our eyes and the light which experience gives is a lantern at the stern, which shines only on the waves behind us! $!^{3}$

\section{J Emby}

AngloGold Ashanti Health, Western Deep Levels Hospital, Carletonville demby@anglogoldashanti.com

1. Tipler M. Letter: Straight talking on CT scanning. South African Journal of Radiology 2010;14(2):42.

2. Idaho State University, Radiation Information Network's. Radioactivity in nature. www.physics.isu.edu/ radinf/natural.htm (accessed 9 September 2008).

3. Emby D J. Radiation: Friend and foe. Occ Health Southern Africa 2008;14(5):9-13.

\section{The HPCSA and radiology}

To the Editor: I find the letter by Professor van Niekerk ${ }^{1}$ which was published in the June 2010 edition of the South African Journal of Radiology most interesting. He stated that it was acceptable for specialists such as cardiologists to use ionising radiation for imaging in their practices, but went on to mention 'the proliferation of many diagnostic and therapeutic interventions that are reliant on expensive equipment.

Have you looked up the price of a cardiac angiogram lately? Or the placing of a drug-eluting stent in a carotid artery? The decision to perform these procedures on patients is taken by the cardiologist alone, who, as things have it, performs the procedures too. I know the training a cardiologist receives in radiation, and it is minuscule compared to that which a radiologist receives (a full first year - as a registrar - of instruction in radiation physics, with an entire part of a two-part examination devoted to the subject).

What about the cardiologists in the Western Cape who bought their own multislice CT scanner (talk about expensive equipment), enabling them to do non-catheter angiograms as well? They received NO training in CT physics at all (and employ a radiographer to operate the machine and make impressive images). 


\section{LETTERS}

Radiologists never have the opportunity to self-refer. We are sent patients by our medical colleagues, requesting a specific examination or procedure. The request form has to be forwarded to the medical aids as proof that no additional examinations were performed other than directly requested, in writing.

I know of GPs in my part of the world who routinely perform their own X-rays and ultrasound examinations. You are correct; besides all the safety issues, such as lead shielding, the quality is nondiagnostic in most cases; patients are told they have gallstones, when they clearly don't, and so the abuse goes on. I know this, because eventually the unwell patients find their way to our practice, and I get to see the X-ray films and listen to the misdiagnosis.

So, let's see if this committee actually has any teeth, or is it all just another useless talk-shop, a typical case of the dogs bark, but the caravan moves on.

This letter will be forwarded, possibly in altered form, to the HPCSA and RSSA

\section{Mark Richardson}

Drs Nisbet, Govender and Associates

The Bay Hospital

Richards Bay

markrich@netactive.co.za

1. van Niekerk JP. The HPCSA and radiology. South African Journal of Radiology 2010;14(2):43.
Professor van Niekerk replies: Thank you for your response. The HPCSA policy is that doctors may practise in fields in which they have had adequate training. If training is perceived to be inadequate, it is up to the person(s)/group believing it to be so to persuade those who are responsible for regulation and for education to address this. It was in response to the inadequacy of the training of general practitioners who owned X-ray equipment that the committee was established.

I share your concern that self-referral is open to considerable abuse. Apart from the dangers of ionising radiation, we should also be concerned about the financial implications of the proliferation of 'safe' imaging modalities, especially ultrasound. Fee-for-service and third-party payment have been shown to be the key drivers of escalating health care costs, and this debate is virtually nonexistent in the public sector. Public rural facilities that have poor radiological facilities and services at least have the possibility of an arm's-length supervision and for ensuring their correction.

\section{JP van Niekerk}

Health \& Medical Publishing Group

Rondebosch

jpvann@hmpg.co.za

\section{CPD Notice}

In the June 2010 edition of the $S A J R$, the questionnaire unfortunately contained errors relating to two questions. The question in both cases should have read Which of the following statements is incorrect? (and not 'correct', as stated). I use a template in compiling the quiz and, of all potential mishaps, the 'in' was omitted. All readers (with the exception of two) recognised the mistake and answered accordingly. Nevertheless, it was decided to credit all participants with their points irrespective of how they read the questions. The questionnaire will be triple-checked, and I do not foresee a repeat occurrence.

Recent audits of some colleagues by the Health Professionals Council of South Africa have indicated a chronic shortage of CPD ethics points, and we considered posting one ethics question per edition. After discussion with Professor JP van Niekerk, we decided to follow an alternative route:

Please note that members of the South African Medical Association (SAMA) and/or the Radiological Society of South Africa (RSSA) may acquire CPD Ethics points by completing the CPD questionnaire in The South African Journal of Bioethics and Law (SAJBL) which is available in online format only at www.sajbl.org.za. The journal is published biannually, in June and December.

Jan Lotz 